do Rio de Janeiro (UFRJ), professora do curso de do Rio de Janeiro (UFRJ), professora do curso de Letras (PROFLETRAS) do Instituto de Ciências Humanas e Sociais da Universidade Federal Rural do Rio Janeiro (UFRRJ).

002-0637-096

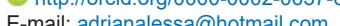

Recebido em: 8/11/2018.

Aprovado em: 6/3/2019.

Endereço para correspondência: Universidade Federal Rural do Rio de Janeiro $\mathrm{BR}-465, \mathrm{Km} 7$

23890-000, Seropédica, RJ, Brasil

\section{A hipótese da primazia do aspecto e telicidade: um estudo de caso duplo}

The primacy of aspect hypothesis and telicity: a double case study

Adriana Tavares Maurício Lessa ${ }^{1}$

Universidade Federal Rural do Rio de Janeiro, Seropédica, RJ, Brasil.

\section{RESUMO}

Este trabalho se propõe a refletir sobre a representação linguística de aspecto a partir de um estudo de caso duplo, com dados de aquisição da linguagem sobre a associação entre aspecto lexical e aspecto gramatical. Seu objetivo principal é avaliar a hipótese da primazia do aspecto, segundo a qual a marcação de tempo-aspecto seria limitada pelo aspecto lexical dos verbos. Para tanto, coloca-se à prova a hipótese de que, no processo de aquisição de aspecto, a associação entre aspecto lexical e aspecto gramatical se baseia na relação entre telicidade e perfectividade. A partir da análise dos dados, a hipótese da primazia do aspecto não pôde ser refutada completamente. Todavia, abarcando diferentes propostas teóricas sobre as propriedades semânticas do VP (sintagma verbal), refuta-se a hipótese de que a primazia do aspecto estaria ancorada na relação entre telicidade e perfectividade. Demonstra-se, ainda, a compatibilidade dos dados com a proposta de telicidade dizer respeito à sintaxe interna ao VP. Por fim, argumenta-se que não haveria leitura composicional de aspecto nas etapas iniciais de aquisição.

Palavras-chave: Aspecto. Telicidade. Hipótese da primazia do aspecto. Composicionalidade aspectual. Aquisição da linguagem.

\section{ABSTRACT}

This paper debates the linguistic representation of aspect based on a double language acquisition study case with data on the association of lexical and grammatical aspect. Its main objective is to evaluate the primacy of aspect hypothesis, according to which tense-aspect markers are limited to some lexical aspect classes of verbs. In order to do so, it tests the hypothesis that, in the language acquisition process, the association between lexical and grammatical aspect is anchored on the relationship between telicity and perfectivity. Based on data analysis, the primacy of aspect hypothesis could not be completely refuted. However, considering different theoretical proposals on the semantic properties of the VP, we refute the hypothesis that primacy of aspect is anchored in the relationship between telicity and perfectivity, considering different proposals of semantic aspectual classification. We also demonstrate through data analysis the appropriateness of the proposal of telicity as being concerned with the internal syntax of the VP. Finally, we argue that there would be no compositional reading of aspect in the initial stages of language acquisition.

Keywords: Aspect. Telicity. Primacy of aspect hypothesis. Aspectual compositionality. Language acquisition. 


\section{Introdução}

$\mathrm{N}$

os últimos cinquenta anos, o estudo de aspecto passou a extrapolar a visão do fenômeno como mera codificação morfológica. Essa expansão se deve ao reconhecimento da contribuição de diferentes elementos sentenciais para a construção do significado aspectual (VERKUYL, 1972, 2002; COMRIE, 1976; SMITH, 1991, entre outros). Com isso, no âmbito da gramática gerativa, surge o desafio teórico de reconhecer os limites entre a sintaxe e a semântica lexical na caracterização de aspecto, questão sobre a qual este artigo se debruça.

Nesse empreendimento assumido pela linguística formal, pesquisas sobre o processo de aquisição da linguagem podem trazer contribuições, uma vez que os estágios iniciais de desenvolvimento da linguagem parecem indicar a existência ou a ausência de análises sintáticas mais complexas. Esse tipo de reflexão sobre a realização sintática no desenvolvimento da linguagem fundamenta, por exemplo, a hipótese da primazia do aspecto ou hipótese do aspecto, adotada por diversos pesquisadores ${ }^{1}$, investigada neste trabalho.

Segundo a hipótese da primazia do aspecto, crianças em fase de aquisição - e até mesmo aprendizes de uma segunda língua - são influenciadas pelo aspecto lexical de verbos ou predicados na aquisição dos marcadores de tempo e aspecto. Uma vertente relacionada a essa visão, chamada inicialmente de hipótese do tempo defectivo absoluto, é retomada neste artigo para guiar a análise dos dados. Segundo essa hipótese, durante o processo de aquisição, situações télicas (achievements e accomplishments) seriam exclusivamente associadas à morfologia de perfectivo e situações

1 E.g., ANDERSEN, 1986; ANDERSEN; SHIRAI, 1996; BARDOVI-HARLIG, 2000. atélicas (estados e atividades) seriam exclusivamente associadas à morfologia de imperfectivo ${ }^{2}$.

A hipótese da primazia do aspecto é muito abordada em estudos sobre a aquisição de aspecto, porém costuma ser associada ao processo de descrever a emergência de combinações entre aspecto lexical e aspecto gramatical. Nesse tipo de abordagem, assume-se uma visão ontológica das classes aspectuais, no sentido ressaltado por Verkuyl (2002), em que verbos refletiriam categorias semânticas de forma ontológica, estritamente no nível lexical. Neste artigo, retoma-se a hipótese e discutem-se, do ponto de vista sintático, as propriedades semânticas do aspecto lexical e sua relação com a noção de composicionalidade aspectual no nível do sintagma verbal (doravante VP).

Logo, tem-se como objetivo específico avaliar a hipótese de que, no processo de aquisição de aspecto, a associação entre aspecto lexical e aspecto gramatical se ancora na relação entre telicidade e perfectividade. Refutar ou não essa hipótese implica abarcar diferentes arcabouços teóricos acerca do caráter lexicalista ou sintático do VP. Portanto, a análise dos dados considera diferentes propostas teóricas sobre as propriedades sintáticosemânticas inerentes às classes aspectuais do VP.

Como metodologia, adota-se um estudo de caso duplo, com dados secundários, para análise da produção verbal dos estágios iniciais de aquisição da linguagem. Metodologicamente, este trabalho se distingue por: selecionar períodos mais iniciais da aquisição (no período entre 1 ano e 6 meses e 2 anos e 2 meses), focalizar sua análise nos types linguísticos e incluir a análise qualitativa de duas línguas (inglês e português).

2 Cf. ANDERSEN, 1989; ANDERSEN; SHIRAI, 1994; WEIST et al., 1984. 
As classificações dos tipos de aspecto lexical apresentam variações de acordo com o arcabouço teórico adotado, tornando ainda mais desafiadora a pesquisa sobre aquisição de linguagem (ANDERSEN; SHIRAI, 1994, p.541). Por isso, neste artigo, avalia-se a pertinência da hipótese da primazia do aspecto, considerando-se diferentes propostas teóricas sobre as propriedades semânticas do VP, para explicar o processo de aquisição de aspecto em tela.

A partir dessa avaliação, defende-se, na seção 3.1, a pertinência da hipótese da primazia do aspecto quanto aos morfemas refletirem propriedades semânticas do aspecto lexical. Refuta-se, na seção 3.2, a hipótese de que a primazia do aspecto estaria ancorada na relação entre telicidade e perfectividade, considerando diferentes propostas de classificação aspectual semântica. Por fim, na seção 3.3, demonstra-se a pertinência da proposta de telicidade dizer respeito à sintaxe interna ao VP e argumenta-se que não haveria leitura composicional nas etapas iniciais de aquisição.

\section{Metodologia}

Neste artigo, optou-se por um estudo de caso duplo com foco nas produções verbais iniciais, focalizando o intervalo de 1 ano e 6 meses a 2 anos e 2 meses, de falantes de línguas distintas: português e inglês. Essa escolha por um estudo de caso de aquisição se fundamenta na assunção de que o estudo de gramáticas desviantes - entendidas como fruto do processo de aquisição e perda da linguagem - é de extrema relevância para a avaliação das propostas acerca da gramática mental dos indivíduos adultos normais, conforme indicam os movimentos históricos de pesquisa em Linguística e outras áreas do conhecimento.

$\mathrm{Na}$ Linguística, contribuições trazidas por pesquisas com gramáticas desviantes indicam que estudos de grupo e estudos de caso fornecem diferentes perspectivas. Autores como Berndt e Caramazza (1999) e Novaes (2004), por exemplo, ressaltam a importância de estudos de caso na Neuropsicologia, demonstrando como as análises individuais permitem detectar padrões específicos de dissociação que poderiam ser mascarados dentro de um grupo.

Com esse intuito de detectar possíveis padrões mascarados, esta pesquisa analisa dados secundários de produção oral, de caráter longitudinal, de duas crianças do sexo feminino, apresentados por Shirai e Andersen (1995) e Lessa (2015), respectivamente. A informante A é falante nativa de inglês e a informante B, de português. Shirai e Andersen (1995) não informaram a variedade de inglês falada pela criança e a criança investigada por Lessa (2015) era falante de português brasileiro.

Os registros foram originalmente categorizados em propostas de etapas de desenvolvimento linguístico distintas: a informante A, com base em Brown (1973) e a informante B, com base em Scliar-Cabral (1977). Sendo assim, os intervalos disponíveis consideram o desenvolvimento linguístico da criança, e não a idade, mas a partir de critérios distintos. No entanto, após uma análise das características da etapa 1 de ScliarCabral (1977) e das etapas 1 e 2 de Brown (1973), acredita-se que a comparação entre esses intervalos não causa prejuízos à análise do processo de aquisição de aspecto. Logo, para este artigo, selecionaram-se para análise os dados referentes à etapa 1 da informante $\mathrm{A}$, correspondente ao intervalo de idade de $1 ; 6$ a 1;10, e às etapas 1 e 2 da informante $B$, correspondente ao intervalo de idade de $1 ; 8$ a 2;2. A despeito do não prejuízo dessa distinção entre as etapas de desenvolvimento para a análise da aquisição de aspecto, ressalta-se que esse recorte pode ter gerado o desnível observado no número de verbos analisados: há um substancial maior número de realizações verbais da criança $A$ em comparação à criança B. 
Em suma, a seleção dos dados deste artigo se distingue do padrão estabelecido na literatura no que tange a três quesitos:

(i) Ambas as crianças apresentavam idades mais baixas que as que são frequentemente abarcadas em estudos de aquisição, já que os estudos costumam abarcar as etapas mais avançadas do desenvolvimento linguístico, a fim de afastar-se de um número reduzido de produções verbais.

(ii) Comparam-se dados oriundos de línguas distintas, o inglês e o português.

(iii) Apresentam-se os dados com base em uma análise qualitativa dos types, em contraste às costumeiras análises quantitativas de tokens.

Então, avalia-se a emergência dos verbos, independentemente do seu número de realizações, de acordo com suas classes aspectuais lexicais e sua combinação com morfemas perfectivos ou imperfectivos nos estágios mais iniciais de aquisição do inglês e do português. Portanto, este artigo coloca-se como um possível contraponto aos estudos presentes na literatura sobre a hipótese da primazia do aspecto, com o intuito de realçar possíveis características do processo de aquisição que sejam mascaradas pelos tipos de análise adotados tradicionalmente na área.

Finalmente, destaca-se que, embora grande parte dos trabalhos sobre aquisição de aspecto utilize as classes de Vendler como base - como é o caso dos trabalhos dos quais se originam os dados selecionados para este artigo -, a variação quanto aos critérios de análise das propriedades semânticas dessas classes aspectuais representa um grande desafio para comparação de estudos e, consequentemente, avanços na área. A fim de buscar uma unidade em sua análise, este artigo retomou a classificação dos dados apresentados originalmente pelos autores, verificando-a com base em critérios e características propostas por Dowty (1979), em seu capítulo abarcando as classes aspectuais dos verbos e predicados verbais.

\section{Dados}

Nesta seção, destacam-se as primeiras combinações entre aspecto lexical e gramatical na fala das crianças. Além disso, debate-se a escolha por se revisar a classificação de determinados verbos, considerando-se Dowty (1979), com o intuito de se criar uma unidade no tratamento dos dados.

Inicialmente, esclarece-se que as produções referentes aos verbos de estado foram suprimidas deste trabalho. Essa decisão se deve ao fato de as produções de verbos de estado da criança $\mathrm{A}$ não terem sido fornecidas em sua totalidade no trabalho original. Além disso, os dados fornecidos parcialmente envolviam outro tipo de debate acerca do uso de morfologia progressiva com verbos estativos no inglês (como em "seeing" e "needing"). Embora Shirai e Andersen (1995) não tragam essa questão à tona, acreditase que esses dados não permitiriam um debate claro acerca do que seriam fenômenos do processo de aquisição da língua e do que seriam fenômenos da língua inglesa, que tem exibido padrões mais permissivos de marcação morfológica para verbos de estado, em semelhança ao português ${ }^{3}$.

Portanto, os dados foram organizados em dois quadros. Neles, destacamse as combinações entre aspecto lexical e gramatical, ou seja, a combinação entre a marcação morfológica (perfectiva ou imperfectiva progressiva) e a classe aspectual dos verbos (atividade, achievement ou accomplishment).

O Quadro 1 mostra os verbos com marcação perfectiva produzidos pelas crianças. Conforme se observa, os verbos produzidos pela criança A são achievements. Os verbos produzidos pela criança B apresentam a mesma tendência. Portanto, destaca-se a restrição de combinação da marcação perfectiva à classe aspectual achievement.

3 Cf. BERTINETTO, 2000; BITTENCOURT, NAVES; LUNGUINHO, 2016; GUIMARÃES, 2017; LEECH, 2004 para discussões mais profundas sobre verbos de estado no inglês e no português. 
Quadro 1 - Marcação perfectiva por classe aspectual

\begin{tabular}{|l|l|l|}
\hline Fonte: & Baseado em Shirai e Andersen (1995) & Lessa (2015) \\
\hline Criança: & A $(1 ; 6-1 ; 10)$ & B $(1 ; 8-2 ; 2)$ \\
\hline Atividade & & \\
\hline Accomplishment & & \\
\hline Achievement & fell, throwed, found & pulou, rasgou, acabou, caiu, dormiu \\
\hline
\end{tabular}

Fonte: Elaborado pela autora.

Os verbos produzidos pela criança A são classificados de acordo com as concepções de Dowty (1979). Na fala da criança B, determinadas classificações dos verbos como achievement são justificadas por Lessa (2015): "pulou", por seu uso após um gato pular de um patamar para outro; "rasgou", por se referir a um resultado fruto de uma situação de caráter instantâneo com ausência de agentividade; e "dormiu", por se referir à transição do estado de alerta ao estado de adormecimento. Tais sentidos são compatíveis com a análise de Dowty $(1979$, p. 53, 68) para achievement, no que tange à mudança de estado físico ou de local.

O Quadro 2 mostra os verbos com marcação imperfectiva progressiva produzidos pelas crianças. Conforme se observa, no caso da criança A, a marcação imperfectiva progressiva se associa às classes de verbo atividade e accomplishment, embora os autores do trabalho original ressaltem que, na etapa 1, as primeiras realizações da forma progressiva pela criança A tenham sido verbos de atividade ou achievements "usados de forma iterativa" (SHIRAI; ANDERSEN, 1995, p.753). No presente trabalho, achievements iterativos foram classificados como atividade. No caso da criança B, a marcação imperfectiva também abarca verbos de atividade e accomplishment. No entanto, os verbos classificados como accomplishment não apareciam acompanhados de complemento verbal, o que pode levar a uma defesa de que indicariam, então, atividade ou, ao menos, as crianças ainda o interpretariam como tal.
Quadro 2 - Marcação imperfectivo progressiva por classe aspectual

\begin{tabular}{|l|l|l|}
\hline Fonte: & Baseado em Shirai e Andersen (1995) & Lessa (2015) \\
\hline Criança: & A $(1 ; 6-1 ; 10)$ & B (1;8-2;2) \\
\hline Atividade & $\begin{array}{l}\text { sleeping, eating, dancing, going, singing, } \\
\text { crying, smiling, talking, comforting, } \\
\text { flying, thinking, working, barking, } \\
\text { holding, drinking, drawing, washing, } \\
\text { looking, swinging, sitting, watching, } \\
\text { blowing, flopping around*, jumping*, } \\
\text { testing*, bouncing*, banging* }\end{array}$ & $\begin{array}{l}\text { dormindo, dançando, mexendo, } \\
\text { comendo }\end{array}$ \\
\hline Accomplishment & $\begin{array}{l}\text { eating aspirin, changing Georgie, } \\
\text { washing leg, cleaning floor, putting toy*, } \\
\text { going home* coming*, going down*, } \\
\text { lying down**, sitting down**, hiding*, } \\
\text { coming out**, feeling better*** }\end{array}$ & vindo, descendo \\
\hline Achievement & & \\
\hline
\end{tabular}

Fonte: Elaborado pela autora.

Determinadas classificações de produções da criança A, no quadro 2, são revistas para este artigo com base nos comentários fornecidos por Shirai e Andersen (1995), já que não se obteve acesso ao corpus original. Os verbos marcados com um asterisco haviam sido classificados como achievements. Considerando os exemplos fornecidos por Dowty (1979) e seus critérios para distinguir as classes, para a presente análise, foram reclassificados como atividades ou accomplishments. Os verbos "jumping", "testing", "bouncing" e "banging" foram classificados como atividades devido ao seu teor iterativo, validado pelo teste de que " $A$ is (now) $v$-ing" implica que "A has v-ed". Os verbos "putting toy", "going home", "coming" e "going" foram considerados accomplishments locativos, sob a lógica de que representariam sintagmas de dois locais, derivados ou não de atividade, com um estado resultante locativo, conforme os verbos "put", "place" e "fly to $N P^{\prime \prime}$ listados por Dowty (1979, p. 69). Seguindo esse mesmo entendimento, os verbos "lying down", "sitting down, "hiding" e "coming out", marcados com dois asteriscos, que haviam sido classificados como atividade, foram 
reclassificados como accomplishments, já que "hide", "sit" e "lie" chegam a ser listados pelo autor como tal.

Por fim, o verbo "feeling better", marcado com três asteriscos, havia sido originalmente classificado pelos autores como estado. Todavia, conforme Dowty (1979, p. 60), verbos de percepção física podem ser estado, atividade ou achievement. "Feeling better" é uma expressão de difícil classificação. Dowty (1979, p. 66) afirma que o verbo "feel", como verbo de percepção física, é tanto achievement quanto estado (DOWTY, 1979, p. 66). No entanto, o autor também classifica "recover from illness" como accomplishment (DOWTY, 1979, p. 54). Por semelhança semântica entre o processo de se recuperar de uma doença e se sentir melhor, que se refere a mudança gradual de estado físico, que precisa alcançar um ponto de culminação para concretizar-se, optou-se por classificar a expressão "feeling better" como accomplishment.

Em resumo, conclui-se que o aspecto gramatical expresso pela morfologia perfectiva combinou-se a verbos de aspecto lexical achievement e o aspecto gramatical expresso pela morfologia imperfectiva progressiva combinouse a verbos de aspecto lexical atividade e accomplishment. Além disso, apresenta-se o fato de os autores dos trabalhos originais terem destacado que, longitudinalmente, achievements e atividades emergiram antes de accomplishments. A partir desses dados, analisam-se, nas próximas seções: (i) o cumprimento das sistematizações previstas pela hipótese da primazia do aspecto; (ii) a pertinência da hipótese de que telicidade determinaria a marcação perfectiva e (iii) o papel da telicidade na composicionalidade aspectual entre VP e marcação morfológica.

\section{Análise dos dados}

A hipótese da primazia do aspecto se refere ao "fenômeno de limitar um marcador de tempo-aspecto a uma classe restrita de verbos, de acordo com o aspecto inerente do verbo" no processo de aquisição da linguagem (ANDERSEN; SHIRAI, 1996, p. 529, tradução nossa) ${ }^{4}$. Em outras palavras, haveria primazia do aspecto pelo fato de a morfologia de tempo e aspecto gramatical ser definida pelo aspecto lexical, ou seja, o aspecto semântico, inerente ao verbo, determinaria sua marcação morfológica de aspecto e tempo. Segundo Shirai e Andersen (1995), no que tange a essa relação entre aspecto lexical e aspecto gramatical, podem-se tomar como expectativa, no processo de aquisição da linguagem, as seguintes sistematizações:

1) As crianças associam a morfologia de perfectivo passado a verbos de aspecto lexical achievement e accomplishment (por exemplo: "achou" e "comeu a banana", respectivamente), estendendo, por fim, a associação às classes de atividade e estado (por exemplo, "correu" e "amou").

2) Em línguas que apresentam marcação de aspecto gramatical imperfectivo contínuo progressivo, essa morfologia se associa, inicialmente, ao aspecto lexical atividade (por exemplo: “está comendo") e, posteriormente, aos tipos de aspecto lexical accomplishment e achievement (por exemplo, "está comendo um bolo" e "está morrendo").

3) A marcação do aspecto gramatical imperfectivo contínuo progressivo não se estende a verbos de aspecto lexical estado (por exemplo, "está amando").

Neste artigo, a análise da hipótese da primazia do aspecto se guia pela avaliação do atendimento das sistematizações 1 e 2 . A sistematização 3, que se refere a verbos de estado, foi excluída da análise pelos motivos expostos na seção 2 .

${ }^{4}$ Do original: This phenomenon of limiting a tense-aspect marker to a restricted class of verbs, according to the inherent aspect of the verb, is known as the Primacy of Aspect (POA). 
Esclarece-se que a avaliação da hipótese da primazia do aspecto toma por base os dados apresentados nos Quadros 1 e 2, da seção 2. Para amparar o debate, a análise desse atendimento (ou não) das expectativas é esquematizado no Quadro 3.

Quadro 3 - Expectativa e resultado de associação do aspecto gramatical ao aspecto lexical

\begin{tabular}{|l|l|l|l|}
\hline \multicolumn{4}{|c|}{ Testagem da Hipótese da Primazia do Aspecto } \\
\hline ASPECTO & \multicolumn{3}{c|}{ LEXICAL } \\
\hline GRAMATICAL & Expectativa & Criança A & Criança B \\
\hline Perfectivo & $\begin{array}{l}\text { - achievement } \\
\text { - accomplishment }\end{array}$ & - achievement & - achievement \\
\hline $\begin{array}{l}\text { Imperfectivo } \\
\text { Contínuo Progressivo }\end{array}$ & $\begin{array}{l}\text { - atividade } \\
\text { - accomplishment } \\
\text { - achievement }\end{array}$ & $\begin{array}{l}\text { - atividade } \\
\text { - accomplishment }\end{array}$ & $\begin{array}{l}\text { - atividade } \\
\text { - accomplishment }\end{array}$ \\
\hline
\end{tabular}

Fonte: Elaborado pela autora.

A expectativa 1 refere-se à marcação perfectiva. No Quadro 3, observase que ambas as crianças realizaram marcação perfectiva apenas com verbos de culminação. A expectativa de marcação perfectiva de accomplishments não se realizou. Logo, o cumprimento da expectativa 1 foi parcial.

Já a expectativa 2 refere-se à marcação imperfectiva progressiva. Nesse quesito, as crianças A e B marcaram verbos de atividade e accomplishment. Ainda que as classificações de achievements revistas como de accomplishments, na seção 2, fossem questionadas, poderia se pensar que a criança A já havia alcançado um estágio de desenvolvimento linguístico superior ao da criança B no momento do registro. Isso significa que a combinação de achievement com marcação imperfectiva progressiva também estaria de acordo com a expectativa proposta pela hipótese da primazia do aspecto. Pode-se dizer, então, que a expectativa 2 se cumpriu.
Portanto, a expectativa 1 se cumpriu parcialmente, enquanto a expectativa 2 se cumpriu plenamente. Especificamente, tem-se como principal quebra de expectativa a marcação morfológica dos accomplishments. A expectativa seria que a marcação perfectiva de accomplishments antecedesse a marcação imperfectiva, o que não ocorreu. Ao contrário, nos dados de ambas as crianças, as primeiras realizações de accomplishments receberam estritamente marcação imperfectiva progressiva. Por fim, destaca-se, ainda, que nenhum dos verbos reclassificados neste trabalho haviam sido originalmente classificados como accomplishments. Logo, ainda que se considerasse, nesse trabalho, a classificação original dos verbos, a expectativa de combinação dos accomplishments à marcação perfectiva não teria sido atendida.

\subsection{Considerações quanto à hipótese da primazia do aspecto}

Com base na análise dos dados das duas crianças do português e do inglês, cabem certas considerações. Para tanto, relembra-se que, conforme apresentado na seção 2 , no início da etapa 1 do desenvolvimento linguístico: (i) o aspecto lexical achievement combinou-se estritamente ao aspecto gramatical perfectivo e (ii) o aspecto lexical atividade combinou-se estritamente ao aspecto gramatical imperfectivo progressivo e (iii) o aspecto lexical accomplishment combinou-se estritamente ao aspecto gramatical imperfectivo progressivo.

Sendo assim, a despeito do não atendimento das expectativas propostas pelas sistematizações de Shirai e Andersen (1995) - fato que não é observado no trabalho original dos autores, no que tange à criança A -, tanto o perfectivo quanto o imperfectivo demonstraram associações padronizadas e restritas a determinados tipos de aspecto lexical. Conforme prevê originalmente a hipótese da primazia do aspecto, de forma mais ampla, os morfemas se relacionaram a classes restritas de verbos. Logo, não se pode dizer que a hipótese foi refutada. 
Mais do que isso, as classes aspectuais, inicialmente, associaram-se a apenas uma marca morfológica. Atividades e accomplishments associaramse estritamente ao imperfectivo contínuo progressivo e achievements, inicialmente, só recebiam marcação perfectiva.

No entanto, questionam-se as sistematizações previstas por Shirai e Andersen (1995), especialmente, no que tange à combinação de accomplishments estritamente ao imperfectivo progressivo. Nessa direção, cabe destacar que outros conhecidos estudos sobre aquisição de aspecto vão ao encontro da ideia de restrição da marcação morfológica, mas destacando outras classes aspectuais.

Antinucci e Miller (1976), por exemplo, ao investigarem a aquisição do italiano e inglês, observaram o uso da flexão de passado com verbos que indicam uma mudança de estado com um resultado claro. No inglês, apenas os verbos indicativos de eventos télicos e pontuais, expressando um "fim de estado", teriam sido produzidos com flexões no passado.

Bloom et al. (1980 apud ANDERSEN, 1989) também apontaram restrição de marcação morfológica, adotando uma categorização aspectual distinta. Os autores indicaram os seguintes padrões nas marcações morfológicas no processo de aquisição do inglês. Verbos com os traços [+durativo] e [-completivo $]^{5}$ associaram-se ao afixo -ing (compatível com o imperfectivo progressivo), como em "playing". E verbos com os traços [-durativo] e [+completivo], que caracterizariam eventos pontuais, se associaram a formas irregulares do passado, como em "broke".

Como se sabe, tradicionalmente, a comunhão das propriedades telicidade e pontualidade caracteriza achievements. Portanto, ambas as pesquisas mencionadas indicam a prevalência de marcação perfectiva de um tipo de 5 Os autores adotam como classificação uma divisão entre ação e estado. As ações seriam subdivididas,
considerando-se a carga semântica positiva ou negativa dos traços semânticos [ \pm durativo] e [ \pm completivo]. classe aspectual - no caso, achievements -, em acordo com o presente estudo, mas sem menção à combinação de accomplishments à marcação perfectiva. Resta, então, esclarecer a não marcação perfectiva de accomplishments, do ponto de vista teórico, em desacordo com a expectativa proposta por Shirai e Andersen (1995), uma vez que ambas as crianças do presente estudo já haviam estendido a marcação de progressivo a accomplishments sem evidências de marcação perfectiva dessa classe aspectual.

Comumente, a marcação perfectiva de verbos achievement e accomplishment é atribuída à saliência de uma das propriedades semânticas que eles compartilhariam: telicidade ${ }^{6}$. Como a marcação perfectiva não se estendeu aos accomplishments, uma análise minuciosa das propriedades semânticas que os caracterizam poderia contribuir para entender sua associação ao imperfectivo progressivo. A partir dessa análise, pode-se pensar se tal associação reflete a saliência de outra propriedade semântica desse aspecto lexical, que não seja telicidade.

Em suma, esta análise ressalta a pertinência da hipótese da primazia do aspecto, mas apenas no que tange à ideia de os morfemas refletirem propriedades semânticas do aspecto lexical. Com base nessa assunção, discute-se na próxima seção a possível relação entre telicidade e perfectividade.

\subsection{Considerações quanto à relação entre telicidade e perfectividade}

A fim de complementar o debate acerca da hipótese da primazia do aspecto, espera-se dar conta das quebras de expectativa apresentadas na seção anterior. Nessa seção, surgiram como pontos principais de análise: a exclusiva marcação perfectiva de achievements e a marcação imperfectiva progressiva de accomplishments.

6 Cf. ANDERSEN, 1989; SLABAKOVA; MONTRUL, 2008. 
Sendo assim, a quebra de expectativa principal diz respeito à emergência de accomplishments não combinada à marcação de perfectivo na fala de ambas crianças, contrariando a expectativa 1 prevista pela hipótese da primazia do aspecto, apresentada na seção 3. Levando em consideração essa emergência de accomplishments associadas ao imperfectivo progressivo, coloca-se à prova a hipótese de que a primazia do aspecto estaria ancorada na relação entre telicidade e perfectividade, prevista pela hipótese do tempo defectivo absoluto. Essa hipótese, com proposta semelhante à das expectativas da hipótese da primazia do aspecto, prevê que situações télicas se combinariam ao perfectivo e situações atélicas se combinariam ao imperfectivo. Embora tenha recebido muitas críticas por atribuir essa restrição de combinação sintático-lexical a uma limitação cognitiva da criança, a relação entre telicidade e perfectividade é comumente referida em estudos de aquisição, especialmente na língua inglesa ${ }^{7}$.

Para testar essa hipótese, consideram-se as propostas de diferentes autores sobre telicidade. Como telicidade é uma das propriedades semânticas que compõem o aspecto lexical, contemplam-se propostas de propriedades semânticas do aspecto lexical diversas. Por isso, a classificação de verbos adotada na análise dos dados das crianças A e B - com base em Vendler (1967) e outros autores contemplados por Dowty (1979) - é retomada sob outra perspectiva, de forma mais detalhada. Nessa perspectiva, focalizamse as propriedades semânticas do aspecto lexical a partir de diferentes propostas de propriedades semânticas do aspecto lexical, abarcando, nesta seção, Smith (1991) e Comrie (1976).

A proposta de propriedades semânticas adotada por Smith (1991) é apresentada no Quadro 4. Recorrendo-se a ela, trabalha-se com as tradicionais propriedades semânticas propostas para compor as classes

Cf. ANDERSEN; SHIRAI, 1994; WEIST et al., 1984. aspectuais de verbos (ou sintagmas verbais), conforme o tipo de situação: estatividade (em oposição à dinamicidade); duratividade (em oposição à pontualidade) e telicidade (em oposição à atelicidade).

Quadro 4 - Traços dos tipos de situação

\begin{tabular}{|l|c|c|c|}
\hline Situação & Estativa & Durativa & Télica \\
\hline estado & {$[+]$} & {$[+]$} & - \\
\hline atividade & {$[-]$} & {$[+]$} & {$[-]$} \\
\hline accomplishment & {$[-]$} & {$[+]$} & {$[+]$} \\
\hline achievement & {$[-]$} & {$[-]$} & {$[+]$} \\
\hline
\end{tabular}

Fonte: Adaptado de Smith (1991, p. 30).

A autora define situações télicas e atélicas referindo-se ao termo "ponto final natural" (SMITH, 1991, p. 29). Eventos atélicos, como as atividades, seriam processos sem ponto final intrínseco, podendo ter um ponto final arbitrário a qualquer tempo. Já eventos télicos, como achievements e accomplishments, seriam voltados para um objetivo intrínseco ao evento, constituindo seu ponto final natural, independentemente de agentividade.

Retomando a hipótese de que telicidade determinaria perfectividade, poderia se pensar, então, que, no caso da emergência de achievements combinados ao perfectivo, o traço de telicidade que compõe essa classe determinaria sua combinação com o perfectivo para as crianças, por meio da leitura do traço [+télico]. Porém, accomplishments também teriam como uma de suas propriedades semânticas o traço [+télico] e não foram combinados ao perfectivo. Parece que a proeminência de telicidade não explicaria o fato de accomplishments, nos dados analisados neste artigo, não serem associados ao perfectivo, mas sim ao imperfectivo, em suas primeiras ocorrências. Portanto, seguindo Smith (1991), a hipótese deste artigo de 
que, no processo de aquisição de aspecto, a associação entre aspecto lexical e aspecto gramatical se ancora na relação entre telicidade e perfectividade seria refutada.

Em uma direção oposta à de Smith (1991), mas considerando as mesmas oposições semânticas, Comrie (1976, p.47) defende que achievements são atélicos. Como essas situações não incorporam o processo que acarreta seu ponto terminativo, não haveria ponto final evidente. Sendo assim, para o autor, apenas accomplishments seriam télicos.

Considerando-se achievements atélicos e accomplishments télicos, os dados iriam na direção contrária à ideia de associação entre telicidade e perfectividade. Achievements, que seriam considerados atélicos, combinaram-se ao perfectivo e accomplishments, que seriam télicos, não. Assim, telicidade se desvincularia de perfectividade. Isto é, mais uma vez, conforme Comrie (1976), a hipótese deste trabalho seria refutada.

Nesta seção, consideraram-se as classes aspectuais com base na propriedade semântica telicidade como inerente ao aspecto lexical. Em conclusão, analisando-se os dados das crianças, a hipótese de que a primazia do aspecto estaria ancorada na relação entre telicidade e perfectividade foi refutada, considerando-se tanto a proposta de classificação aspectual semântica de Smith (1991) quanto a de Comrie (1976).

\subsection{Considerações quanto à composicionalidade aspectual}

Na seção anterior, debateu-se a relação entre telicidade e perfectividade com base nas propostas de propriedades semânticas de Smith (1991) e Comrie (1976), que possuem um maior caráter lexicalista. Como contraponto, cabe colocar em discussão os dados deste trabalho sob outras visões de telicidade, de maior caráter sintático, de um ponto de vista composicional. Portanto, nesta seção, discutem-se os dados a partir das propostas de Rothstein (2008) e Verkuyl (2002).
Para Rothstein (2008), telicidade não é uma propriedade semântica de verbos, enquanto categoria sintática (nesse sentido, doravante Vs), mas sim uma propriedade dos VPs. Logo, não é possível caracterizá-la em termos de classes verbais ou da caracterização de traços do núcleo. Para a autora, as quatro classes de Vendler restringem a forma como os eventos são caracterizados. Ela sugere, então, que essas classes derivam de dois traços básicos, que não incluem telicidade, quais sejam: (i) se são ou não inerentemente estendidos de forma temporária e (ii) se eles expressam ou não eventos de mudança.

Na mesma direção de Rothstein (2008), já valorizando o caráter sintático interno ao VP e excluindo telicidade da gama de propriedades semânticas que compõe o verbo, Verkuyl (2002) também associava telicidade ao nível do VP. Mais do que isso, para o autor, a categorização do aspecto lexical se baseia sempre na ideia de composicionalidade aspectual. Haveria, assim, três tipos de classes aspectuais, todas resultantes da composicionalidade aspectual: estados, eventos e processos. Segundo o autor, a noção de achievement seria a única suspeita do ponto de vista da composicionalidade aspectual e, por isso, é excluída de sua proposta de classes aspectuais.

Essa é uma perspectiva interessante para explicar o fato de o aspecto lexical achievement emergir antes de accomplishments na produção de ambas crianças. Achievement é um aspecto lexical que gera dificuldades e divergências quanto à classificação de suas propriedades semânticas, mas é o tipo de aspecto lexical a emergir mais cedo na produção linguística da criança. Portanto, em encontro a Verkuyl (2002), defende-se uma especial simplicidade inerente à interpretação desse tipo de aspecto lexical.

A partir da informação de que telicidade advém de composicionalidade e achievements não envolvem composicionalidade, constata-se que telicidade não determinaria a marcação perfectiva de achievements. No entanto, permaneceria sem explicação, diante dessa proposta teórica, a exclusiva 
marcação perfectiva de verbos achievement. Ainda assim, considerando-se que, conforme Verkuyl (2002), achievement é uma classe verbal que não é oriunda de composicionalidade aspectual e, conforme Rothstein (2008), telicidade é um traço do VP e não dos verbos, pode-se dizer que, seguindo ambos os autores, a hipótese deste trabalho de que a telicidade se relaciona à perfectividade também seria refutada, com base nos dados das crianças A e B.

Ambos os autores ressaltam, portanto, a complexidade do traço [ ttélico], que seria determinado de forma composicional. Assim, atribui-se à telicidade maior caráter sintático e eventos télicos apenas emergeriam da combinação entre verbo e argumento interno, condizentes com a sintaxe interna ao VP. Com base nessa visão, Verkuyl (2002) propõe que a classificação aspectual em estado, processo e evento seria resultante da seguinte álgebra de traços, conforme ilustra a Figura 1.

Figura 1 - Construção das três classes aspectuais

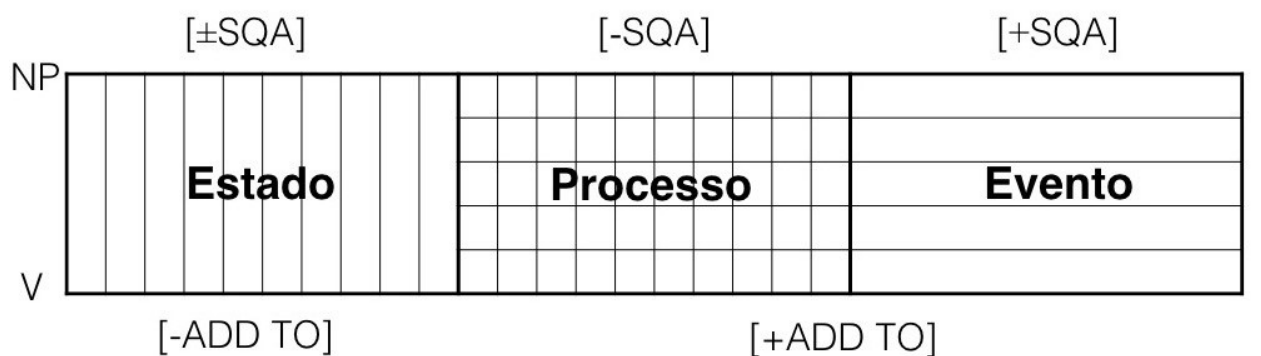

Fonte: Verkuyl (2002, p. 205).

As informações de traços aspectuais estariam codificadas a partir da associação entre os traços do sintagma nominal (doravante NP) e do verbo. A propriedade semântica do verbo [+ADD TO] expressaria progresso dinâmico, mudança ou não estatividade. Já a propriedade [+SQA] expressaria que o NP pertence a uma quantidade específica de coisas ou massa denotada por seu núcleo nominal, relacionando-se à noção de partitividade e de quantificação. Na proposta de composicionalidade do autor, a álgebra de traços seria guiada pelo Princípio Mais, que determina que um valor negativo interno ao VP seria suficiente para gerar uma leitura de aspecto gramatical imperfectivo nos níveis sintáticos superiores (ou seja, no nódulo de tempo ou aspecto).

Com base nessa álgebra, podem-se retomar alguns dados das crianças A e B. Em uma análise da produção da criança A, observa-se a marcação imperfectiva progressiva de atividades e accomplishments (que seriam processos e eventos, respectivamente, em uma perspectiva composicional). Ao se analisar as características desses VPs do Quadro 2, observa-se a forte presença de verbos intransitivos, ou seja, verbos sem complemento interno compondo o VP. A despeito da impossibilidade de acesso aos dados contextualizados da criança $\mathrm{A}$, observa-se no quadro um grande número de verbos de atividade que aparecem exclusivamente em estruturas intransitivas: "sleeping", "dancing", "singing", “crying", "smiling", “flying", “working”, "barking", "flopping around", "jumping", "going home", “coming”, "going down", "lying down", "sitting down", "hiding", "coming out" e "feeling better". No caso desses verbos, pode-se afirmar que não há leitura composicional de complemento interno. Já que não há NP, o único traço lido seria a propriedade semântica do verbo [+ADD TO].

No caso dos verbos que podem ser transitivos ou não, seria necessário um acesso aos dados integrais para confirmar a estrutura do VP e ter seus possíveis complementos. Assim, haveria mais evidências sobre o possível processo sintático interno ao VP, embora se saiba que, nesta etapa, a produção das crianças não costuma incluir nem determinantes. 
Apesar dessa deficiência da análise, considerando os verbos transitivos com complemento disponível, todos accomplishments, que podem ser analisados do ponto de vista da composicionalidade aspectual, os complementos são, majoritariamente, objetos não quantificados, ou seja, de valor [-SQA], como é o caso de "eating aspirin", "washing leg" e "cleaning floor". Sendo assim, esses VPs analisados possuem verbos de valor aspectual [+ADD TO] e complementos de valor aspectual [-SQA]. De acordo com Verkuyl (2002), essa combinação compõe processos (que se assemelham a atividades do ponto de vista aspectual) e não eventos, já que os processos seriam resultantes da associação de verbos de valor aspectual [+ADD TO] com NPs de valor [-SQA] e os eventos seriam resultantes da associação de verbos de valor aspectual [+ADD TO] com NPs de valor [+SQA]. Essa classificação como processo, seguindo o Princípio Mais, induziria uma leitura imperfectiva do VP nos níveis sintáticos correspondentes aos nódulos de tempo-aspecto.

Logo, essa classificação diferenciada das produções como processos parece justificar a combinação desses verbos com a morfologia imperfectiva progressiva, em vez da esperada combinação com o perfectivo. Ainda assim, resta justificar as produções "changing George" e "putting toy", que parecem conter NPs de quantidade especificada, ou seja, de valor [+SQA]. Essa combinação geraria eventos, segundo a classificação Verkuyl (2002), que poderia se combinar ao perfectivo. No entanto, observa-se a ausência de determinante antes do complemento da produção "putting toy", fenômeno típico dessa etapa do desenvolvimento linguístico. Então, é possível considerar isso um indicativo de que os traços do NP não estejam sendo lidos nem no que diz respeito aos traços da propriedade [+-SQA] nem no que diz respeito à composicionalidade aspectual do VP.

Em uma análise da produção da criança B, que é mais restrita, há marcação imperfectiva progressiva de atividades e accomplishments. Mas, em ambos os casos, os verbos ainda não estavam acompanhados por argumento interno, já que se trata dos verbos "dormindo", "dançando", "vindo" e "descendo", a despeito do ponto final inerente às situações. Como não há complemento interno, não há traço [+-SQA] a ser considerado na composição aspectual, logo, os VPs desses verbos (antes classificados como atividades e accomplishments) também seriam considerados processos, do ponto de vista composicional, o que parece autorizar e justificar sua combinação com o imperfectivo progressivo.

Em suma, tanto no caso da criança A quanto no da criança B, ainda parece plausível considerar que não há leitura da álgebra de traços [+ADD TO] com complementos [+SQA], que compõem eventos. Então, em uma perspectiva maturacional, pode-se assumir como tese que ainda não haveria leitura sintática composicional plena de aspecto internamente ao VP nos estágios mais iniciais da aquisição. Isso significaria que telicidade seria subespecificada, em consonância com a proposta de Lessa (2015).

Em uma comparação entre Rothstein (2008) e Verkuyl (2002), vale destacar que, embora Rothstein (2008) faça sua crítica à classificação quadripartite, continua a adotá-la, mas afirma que se referem ao V. De seu ponto de vista composicional, telicidade independe dos traços inerentes a $\mathrm{V}$, que guiariam a categorização dessas quatro classes aspectuais, conforme a classificação de Vendler (1967), em estado, atividade, accomplishment e achievement. Em outras palavras, no nível do VP, determina-se apenas a propriedade telicidade, logo, atividades poderiam compor VPs télicos e accomplishments poderiam compor VPs atélicos.

Sendo independente da classificação de telicidade, portanto, a classificação de verbos como atividade estaria relacionada à combinação entre o traço positivo de ser inerentemente estendido de forma temporária e o traço negativo de evento de mudança. Por outro lado, a classificação de accomplishments estaria relacionada à combinação entre o traço positivo 
de ser inerentemente estendido de forma temporária e o traço positivo de expressar evento de mudança. Ressalta-se, então, a complexidade da classe de accomplishments na classificação de Rothstein (2008), em consonância com a proposta de Verkuyl (2002). Essa visão de Rothstein parece ser uma solução compatível com o problema teórico que emerge dos dados em tela, já que accomplishments emergiram mais tardiamente na fala de ambas as crianças, mas, do ponto de vista da combinação à marcação morfológica, parecem ainda ser lidos como atividades, contrariando as expectativas propostas pela hipótese da primazia do aspecto.

Portanto, a tese de que não haveria leitura composicional internamente ao VP nas etapas iniciais, a princípio, também não pode ser refutada considerando-se Rothstein (2008). Com base na proposta da autora, é plausível a defesa de que os traços inerentes a $V$ determinariam a marcação perfectiva ou imperfectiva, independentemente do traço de telicidade. Além disso, torna-se claro a ideia de telicidade se referir à sintaxe interna do VP e não a uma propriedade semântica de V.

\section{Considerações finais}

O presente artigo apresenta um estudo de caso duplo, analisando a produção linguística referente à expressão de aspecto nos estágios iniciais do processo de aquisição do inglês e do português. Testou-se a hipótese da primazia do aspecto e debateu-se a relação entre telicidade e perfectividade, considerando diferentes propostas teóricas sobre as propriedades sintáticosemânticas internas ao VP.

$\mathrm{Na}$ testagem da hipótese da primazia do aspecto, as expectativas de combinação entre aspecto lexical e aspecto gramatical se cumpriram parcialmente, já que o morfema de aspecto perfectivo não se associou ao aspecto lexical accomplishment. Em vez disso, accomplishment associou- se apenas ao imperfectivo progressivo. A despeito dessa quebra dessa expectativa de combinação, pode-se dizer que a aquisição dos marcadores de tempo e aspecto parece ser restringida pelo aspecto lexical de verbos ou predicados. Portanto, afirma-se que a Hipótese da Primazia do Aspecto não pôde ser refutada completamente.

Ao se colocar à prova a hipótese de que a propriedade semântica telicidade determinaria a marcação perfectiva, consideraram-se quatro propostas teóricas (COMRIE, 1976, SMITH, 1991, VERKUYL, 2002; ROTHSTEIN, 2008). Em todos os casos, a hipótese foi refutada.

Para dar conta da não combinação entre accomplishment e perfectivo nos estágios iniciais de aquisição da linguagem, as propostas de caráter composicional apresentam maior adequação explicativa. Corroborando a ideia de que o aspecto lexical determinaria a escolha morfológica, telicidade estaria excluída desse processo, apresentando-se como um traço diretamente relacionado à sintaxe interna ao VP. Diante dessa concepção, o acesso à interface entre semântica e sintaxe seria tardio, explicando não só as combinações morfológicas, mas também a emergência dos aspectos lexicais achievement e atividade na produção mais inicial das crianças.

Além disso, demonstra-se como a emergência tardia de accomplishments, combinados ao morfema perfectivo, parece alinhar-se à visão de telicidade como aspecto associado à sintaxe interna ao VP. Ou seja, a emergência posterior dessa classe, associada ao imperfectivo, afasta a hipótese de telicidade determinar a associação entre achievements e perfectivo, mas corrobora a hipótese de que telicidade advém da composicionalidade aspectual interna ao VP.

Enfim, destaca-se a contribuição de estudos de aquisição da linguagem, como este, para a validação de propostas teóricas sobre o sistema línguístico. Assim, demonstra-se, conforme Chomsky (1988), a relevância 
da interação entre as duas primeiras perguntas que guiam o programa de investigação gerativa: as teorizações acerca do conteúdo do sistema mental de conhecimentos do falante de uma determinada língua devem se adequar às bases do desenvolvimento desse conhecimento, no processo de aquisição da linguagem.

\section{Agradecimentos}

Agradeço à leitura crítica da professora Adriana Leitão Martins (UFRJ) e às cuidadosas contribuições fornecidas pelos seus avaliadores anônimos, que me permitiram realizar grandes progressos até chegar à versão final deste artigo.

\section{Referências}

ANDERSEN, Roger. La adquisición de la morfologia verbal. Lingüística, [s. l.], v. 1 p. 89-141, 1989.

ANDERSEN, Roger W.; SHIRAI, Yasushiro. Discourse motivations for some cognitive acquisition principles. Studies in Second Language Acquisition, Bloomington, v. 16, p.133-156, 1994. https://doi.org/10.1017/S0272263100012845

ANDERSEN, Roger; SHIRAI, Yasushiro. Primacy of aspect in first and second language acquisition: the pidgin/creole connection. In: RITCHIE, William C.; BHATIA, Tej K. (ed.). Handbook of second language acquisition. San Diego: Academic Press, 1996. p. 527-570.

ANTINUCCI, Francesco; MILLER, Ruth. How children talk about what happened. Journal of Child Language, Cambridge, v. 3, n. 2, p. 169-189, 1976. https://doi. org/10.1017/S0305000900001434

BARDOV-HARLIG, Kathleen. Tense and aspect in second language acquisition: form, meaning and use. Malden: Blackwell, 2000.
BERNDT, Rita Sloan; CARAMAZZA, Alfonso. How "regular" is sentence comprehension in broca's aphasia? It depends on how you select the patients. Brain and Language, Orlando, v. 67, n. 3, p. 242-247, May 1999. https://doi.org/10.1006/brln.1999.2130

BERTINETTO, Pier. The progressive in Romance, as compared with English. In: DÄHL Östen (ed.). Tense and aspect in the languages of Europe. Berlin: Mouton de Gruyter, 2000. p. 559-664.

BITTENCOURT, Marco Túlio; NAVES, Rozana; LUNGUINHO, Marcus. An analysis of the progressive with stative verbs in Brazilian Portuguese. Caderno de Squibs: Temas em Estudos Formais da Linguagem, Brasília, v. 2, n. 2, p. 59-68, 2016.

BLOOM, Lois; LIFTER, Karin; HAFITZ, Jeremie. Semantics of verbs and the development of verb inflection in child language. Language, Washington, v. 56, n. 2, p. 386-412, 1980. https://doi.org/10.1353/lan.1980.0001

BROWN, Roger. A first language: the early stages. Cambridge: Harvard University Press, 1973. https://doi.org/10.4159/harvard.9780674732469

CHOMSKY, Noam. Language and problems of knowledge: the Managua lectures. Cambridge: MIT Press, 1988.

COMRIE, Bernard. Aspect. Cambridge: Cambridge University Press, 1976.

DOWTY, David. Word meaning and montague grammar. Reidel: Dordrecht, 1979. https://doi.org/10.1007/978-94-009-9473-7

GUIMARÃES, Patricia. Verbos de estado e a morfologia de progressivo: um estudo comparativo entre o português do Brasil e o inglês dos Estados Unidos da América. Rio de Janeiro, 2017. Dissertação (Mestrado em Linguística) - Faculdade de Letras, Universidade Federal do Rio de Janeiro, Rio de Janeiro, 2017.

LEECH, Geoffrey. Meaning and the English verb. London: Pearson, 2004.

LESSA, Adriana. Dissociação entre tempo e aspecto à luz da aquisição da linguagem. 2015. Tese (Doutorado em Linguística) - Faculdade de Letras, Universidade Federal do Rio de Janeiro, Rio de Janeiro, 2015. 
NOVAES, Celso. Neuropsychology and linguistic aphasiology: evidence in favor of case studies. Brain and Cognition, New York, v. 55, n. 2, p. 362-364, 2004. https://doi org/10.1016/j.bandc.2004.02.047

ROTHSTEIN, Susan. Theoretical and crosslinguistic approaches to the semantics of aspect. Amsterdam: John Benjamins Publishing Company, 2008. https://doi. org/10.1075/la.110

SCLIAR-CABRAL, Leonor. A explanação linguística em gramáticas emergentes. 1977. Tese (Doutorado em Letras) - Universidade de São Paulo, São Paulo, 1977.

SHIRAI, Yasushiro; ANDERSEN, Roger. The acquisition of tense-aspect morphology: a prototype account. Language, Washington, v. 71, n. 4, p. 743-762, 1995. https://doi. org/10.2307/415743

SLABAKOVA, Roumyana; MONTRUL, Silvina. Genericity and Aspect in L2 Acquisition Language Acquisition, Hillsdale, v. 11, n. 3, p.165-196, 2003. https://doi.org/10.1207/ s15327817la1103_2

SMITH, Carlota. The parameter of aspect. Dordrecht: Kluwer Academic Publishers, 1991.

VENDLER, Zeno. Verbs and times. In: VENDLER, Zeno (ed.). Linguistics in Philosophy. Ithaca: Cornell University Press, 1967. p. 97-121.

VERKUYL, Henk. Aspectual composition: surveying the ingredients. In: UTRECHT PERSPECTIVES ON ASPECT CONFERENCE, 2001. Proceedings [...]. [S. l.: s. n.], 2001. p. 201-219.

WEIST, Richard et al. The defective tense hypothesis: on the emergence of tense and aspect in child Polish. Journal of Child Language, Cambridge, v. 11, n. 2, p. 347-374 June 1984. https://doi.org/10.1017/S030500090000581X 